\title{
Trust and climate
}

\author{
Nico Stehr* \\ Green College, The University of British Columbia, 6201 Cecil Green Park Road, Vancouver, British Columbia, \\ Canada V6T 1 Z1
}

\begin{abstract}
This paper examines common sense representations of the environment with specific reference to climate. Such systems of representation are emergent phenomena, mediated by specific social contexts and evolving in response to different societal events and natural constraints. It is asked what characteristic features are assigned to climate in past and modern society. The conjecture is that our understanding of climate is strongly influenced by experiences with extreme climatic events. Extremes are occasions that reinforce trust and confidence in the normality of climate. Thus, the ways in which extremes are dealt with and explained by society provides an important clue for the semantics of environmental representation generally.
\end{abstract}

KEY WORDS: Social construct of climate Climate extremes Everyday conception of climate

\section{TRUST AND CLIMATE}

'The impression that climate is a constant phenomenon is deeply embedded in everyday consciousness and it is manifest in the profound confidence that any unusual seasonal or annual weather pattern must be compensated for in subsequent periods.'

(Brückner 1890, p. 2)

'Snow has been falling on the cedars. In fact, it was only the seventh white Christmas in six decades and Vancouverites, used to taking their holidays on the wet side, were a little bit discombobulated by the white shellacking they've taken recently... Rest assured the rain will eventually happen here.

(Toronto Globe and Mail, December 26, 1996)

More than a century ago, Eduard Brückner was one of the first climate scientists to write about anthropogenic climate change and variability. He was also deeply concerned about the impact of climate change on societies, the role of different stakeholders and the part the public played (Stehr et al. 1995). Brückner's thesis that the common sense understanding of climate in modern societies is based on a strong belief in the normality of climate is also most noteworthy but remains uninvestigated. By the same token, one of the

\footnotetext{
•E-mail: stehr@interchg.ubc.ca
}

first environmentally conscious scholarly works in the English language, George P. Marsh's ([1864] 1965 , p. 29; year of original publication in square brackets) 'Man and Nature', contends that 'nature left undisturbed so fashions her territory as to give it almost unchanging permanence of form, outline, and proportion.' Marsh's observations echo a view of natural conditions as constant and permanent quite common in Western thought in the nineteenth century. Brückner's attributions, therefore, are in line with widely held assumptions in the scientific community during the nineteenth century.

This paper examines the common sense conception of the environment that members of society have constructed in the course of their long-term encounters with nature. The notion of climate as part of our 'environment' places us in a peculiar relationship to climate because such a concept of the environment invokes the image that humans are at the midpoint of the system and that climate simply surrounds us. Such imagery promotes the idea that climate is there to serve us and can to all intents and purposes be trusted as a faithful agent. With reference to early religious belief systems, Semple (1931, p. 510), using the example of the Mediterranean region, maintained that 'the frequent threat of drought, the powerlessness of the people to deduce any meteorological law, and their helplessness before the forces of nature, all conspired to unite rain 
and religion in the ancient Mediterranean mind.' The chief gods of the times were weather gods powerful enough to regulate climatic conditions and to bestow favorable life-giving water or to withhold such resources. But whether the ancient chief gods as weather gods were merely serene and predictable or whether their temper varied in an inexplicable fashion is unclear. According to Semple (1931, p. 51) 'meteorological functions [of the chief gods] were primitive, fundamental, and persistent.'

With the above in mind, this paper focuses specifically on those systems of representation that have emerged with respect to climate. This is by no means an easy task since the complexity, as well as the sources of the credibility of the social construct of climate and weather, is concealed by the routine, the ease and the frequency with which we use these terms in a variety of contexts. The ease with which we employ these notions suggests, for example, that we have an almost 'natural', intuitive insight into these phenomena. Yet, the very centrality of these terms also hides ambiguity, fragility and perhaps a lack of real comprehension.

From a philosophy of science perspective or from the vantage point of social theory, the constructivist approach used here is in the tradition of Emile Durkheim (e.g. Durkheim [1912] 1965) and proceeds from the assumption that the world as we know it does not codify and categorize itself but is actively ordered, organized and classified by observers. Relevant knowledge about the environment in general and the climate in particular originates within a particular social context that leaves its imprint on what is known, more specifically: on the social construct 'climate' (see also Foucault 1973, Hannigan 1996).

In any event, the question is, what characteristic meanings and features are assigned to climate and to what extent are these attributes of climate an expression of and embodied in highly aggregated and routinized experiences with climate, therefore assuming the status of intuitive ways of conceptualizing the manner in which climate affects and constrains social conduct? 1

Conjecture here is that the understanding of the natural climate is mainly influenced by experiences with extreme climatic events. Thus, the ways in which extremes are dealt with and explained by society provides an important clue for the semantics of environmental representation generally. They permit one to make sense of both common and uncommon natural events.

'Compare the very useful and imaginative discussion of such intuitive characteristics assigned to nature at different periods of time in Böhme (1992, p. 56-76)
In order to understand the meaning and the transformation of the social representation of climate, an attempt has to be made to relate it to its socio-historical origins, to significant features of society and to the impact of the social milieu on the specific articulation of systems of environmental representation (Godelier [1984] 1986, p. 33-38). Although the social construct of climate, as this term indicates, is a set of meanings and practices associated with (natural) climatic conditions - that is, with what are otherwise meaningless physical processes that are transformed into cultural objects and social practices-in the case of climaterelated constructs, the impact of some of the major social institutions, politics and power, is surely less of a factor in its development. For example, in contrast to many other contemporary social and cultural constructs, the normalization and codification of climate as a social artifact is much less imposed or enforced by choices made by the modern state or its representatives, as one of the pre-eminent agents of mental structures in modern society, than say is the case for contemporary orthography (Bourdieu [1991] 1994) or modern landscapes (Greider \& Garkovich 1994). Some of the classical sociological questions about the extent to which beliefs and practices are class-centered, driven by ideological considerations or have to be understood as emanating from different organizational or institutional contexts are therefore less relevant considerations when it comes to an analysis of the common sense understanding of climate.

The practical and political significance of the 'social construct of climate' is quite evident (Stehr \& von Storch 1995). It affects not only the kind of confidence society has in climate and the ways in which it may be prepared to behave toward climate in the future, but it also determines the public's interpretation of 'scientific constructs of climate' and climate change. The robustness, certainty and durability of common sense convictions about climate could become a decisive element in the precarious equation of knowledge, policies and practices.

\section{THE SOCIAL PERCEPTION OF CLIMATE}

It is widely assumed among anthropologists, ethnologists and sociologists that the experience of nature by humans is profoundly transformed in the course of what is often described as the process of 'cultural evolution', social extension (Stehr 1994, p. 29-32) or the civilizing process.

But whether the common sense representation of the environment in general and climate in particular has generally become affectively more neutral or increasingly less relevant and more distanced in the course of 
what Norbert Elias ([1939] 1982) has conceptualized as the 'civilizing process' is difficult to assess. According to Elias, human perception of things and people have become affectively more neutral, less directly driven by human wishes and desires and more determined by experiential orientations. Individuals are compelled by changing social conditions to restrain their momentary affective impulses and rely to a greater degree on observation, restraint, a delay of gratification, etc. On the other hand, the experiences of earlier civilizations with nature is not only more immediate but also more extensive and developed. Social conduct is less emancipated from the exigencies of nature, nature is more directly a source of life and perhaps is often seen as a sphere of risk and danger. It certainly is a realm with which everyone has to contend daily more or less immediately and often in an unmediated manner.

As societies began to emancipate themselves from their environment, including its climatic conditionsignoring for the moment the extent to which the civilizing process changed the climate-such a 'release' from the climate occurred in a stratified fashion. Until quite recently (and in some cases even until today), some occupational groups, the rapidly declining occupations of sailors, mountain farmers, etc., continued to be exposed to the dangers and risks of climate and climatic extremes. Most people now pass their lives indoors. But talk about and fascination with weather, climate and its impact, especially catastrophic events located in the future, does not disappear, perhaps becomes even more frequent.

Whether any preoccupation with catastrophic or extremely improbable future events is a peculiar present-day, perhaps even modern, phenomenon is an empirical question. But if this is indeed the case, the question becomes how to account for such interests. Luhmann (1991, p. 3) suggests that public concern with extremes has to do with linking the cause of these events with individuals or industry. The coverage in the media of global environmental news is at times most prominent in the national media of some countries (Mazur \& Lee 1993, also Lowe \& Morrison 1984. Gamson \& Modigliani 1989, Lacey \& Longman 1993) but then also declines significantly (Mazur in press).

The civilizing process has the effect that nature is seen in a less personal fashion, as less directly related to emotions, as providing a less immediate form of excitement and as constituting less of a 'danger zone'. Once the veil of passions is slowly removed from human consciousness, 'a new world comes into view-a world whose course is friendly or hostile to the individual person without being intended to be so, a chain of events that need to be contemplated dispassionately over long stretches if their connections are to be disclosed' (Elias [1939] 1982, p. 273). The societal system of representation of nature, as a result, can become more object centered or 'scientific' (see Elias 1971). Nature now becomes visible-along with the pacification of social conduct generally-in a new sense; for example, nature becomes aestheticized, it evolves into a place of relaxation and intellectual and physical renewal. And such a transformation of nature sustains the trust in nature gained in earlier times.

\section{OPINION SURVEYS}

To date, the examination of the social construct of climate by social scientists has mainly proceeded with the help of survey data. Public opinion surveys about environmental concerns have been carried out in many countries and for many years now. Here, brief reference will be made to these studies, but the author will not rely on survey results in explicating the genesis and the nature of the common sense conception of climate

Although there is nothing wrong with a quantitative approach and one that invokes survey data, it will be argued here that opinion survey results have been less than illuminating. The results of surveys are somewhat superficial snapshots of public opinion. Survey research tends to methodologically atomize its subjects. It creates only an artificial context within which opinions are elicited. However, the robustness and intensity of views, the tensions, linkages and the supraindividual nature and history of beliefs are poorly represented. Also, the question of the relevance of opinions solicited on the basis of verbal clues for social action remains largely unresolved. Finally, one of the main attributes of the social construct of the nature of climate is, as it will be argued, the trust we confer on climate and its essential normality. These essential attributes are rarely captured in opinion surveys

The trust we extend to nature is disappointed as the result of extreme weather events. But one usually does not know under what conditions opinion surveys may have been carried out. As a result, we do not know whether such disappointments paradoxically also affirm our profound confidence in the basic recurrence of and return to natural normal climatic patterns. ${ }^{2}$

\footnotetext{
${ }^{2}$ In critically analyzing these opinion surveys, I do not want to rehearse at length the important but now well-known standard critique of the inherent limitations of survey research. Some of the usual objections are clearly relevant to my concerns about the common sense conception of climate and this includes the lack of contextual information, the lack of data on the robustness of the opinions, the inability to account for the origins of these views held by the public at a certain time and in different countries of the world. A classic critique of survey research may be found in Cicourel (1964)
} 
Table 1 Perceived dangers of climate change. Percent of respondents in West Germany and West Berlin in October 1989 aged 16 and older who report that climate change and the ozone hole constitute a major environmental threat $(\mathrm{n}=$ 1261). Source: Natur-Umwelt-Barometer. III Welle Oktober/ November 1989, Institut für Demoskopie Allensbach. Germany; reproduced with permission

\begin{tabular}{|lc|}
\hline Total & 87 \\
Male & 89 \\
Female & 85 \\
Age & \\
$16-29$ & 90 \\
$30-44$ & 92 \\
$45-59$ & 83 \\
$60+$ & 83 \\
Place of residence by population & \\
5000 or less & 80 \\
$5000-20000$ & 88 \\
$20000-100000$ & 89 \\
greater than 100000 & 89 \\
\hline
\end{tabular}

Nonetheless, a brief review of recent selected results of opinion surveys in different countries about the issue of climate change or global warming is instructive. In the final analysis these data raise more questions than they are able to answer. ${ }^{3}$

The results summarized in Table 1 show a remarkably large number of affirmative responses. This precludes use of the usual procedure of disaggregating the result by certain demographic attributes of respondents. ${ }^{4}$ Both young and old, urban and rural residents, and females and males are convinced that climate change constitutes a serious environmental threat. One interpretation might therefore be that environmentalism has become an almost universal concern, at least in Germany. Similarly, as one set of recent surveys from around the world demonstrates, the concern with or information about the possible harm that may come from global warming is fairly widespread (Table 2).

However, these findings and differences in public opinion reported to exist in different countries of the world in Table 2 tell us little if anything about the ori-

\footnotetext{
${ }^{3}$ The number of surveys in different countries about environmental attitudes generally is of course very large and cannot be documented let alone be discussed in this context. However, some interesting findings, particularly those based on internationally comparative research designs, may be found in Pierce et al. (1987) and Steger et al. (1989)

${ }^{4}$ Similar results have been obtained in a range of studies for different countries and sets of respondents, for example by Henderson-Sellers (1990); the survey results reported by Samdahl \& Robertson (1989), Dunlap et al. (1994) do not deal specifically with global warming but environmental problems'
}

Table 2. Percentage of respondents in selected countries undicating that global warming is 'a very serious issue' Sources: Bergesen \& Parmann (1994, p. 119) and Dunlap et al. (1994, p. 8)

\begin{tabular}{|lll|}
\hline Canada & $58 \%$ & $\mathrm{n}=1011$ \\
USA & $47 \%$ & $\mathrm{n}=1032$ \\
Brazil & $71 \%$ & $\mathrm{n}=1414$ \\
Chile & $59 \%$ & $\mathrm{n}=1000$ \\
Mexico & $62 \%$ & $\mathrm{n}=1502$ \\
Uruguay & $69 \%$ & $\mathrm{n}=800$ \\
Japan & $47 \%$ & $\mathrm{n}=1434$ \\
Korea (Rep.) & $47 \%$ & $\mathrm{n}=1500$ \\
Philippines & $40 \%$ & $\mathrm{n}=1000$ \\
India & $36 \%$ & $\mathrm{n}=4984$ \\
Turkey & $45 \%$ & $\mathrm{n}=1000$ \\
Hungary & $33 \%$ & $\mathrm{n}=1000$ \\
Poland & $59 \%$ & $\mathrm{n}=989$ \\
Russia & $40 \%$ & $\mathrm{n}=964$ \\
Denmark & $55 \%$ & $\mathrm{n}=1019$ \\
Finland & $34 \%$ & $\mathrm{n}=770$ \\
Norway & $66 \%$ & $\mathrm{n}=991$ \\
Germany & $73 \%$ & $\mathrm{n}=1048$ \\
Great Britain & $62 \%$ & $\mathrm{n}=1105$ \\
Ireland & $63 \%$ & $\mathrm{n}=928$ \\
The Netherlands & $36 \%$ & $\mathrm{n}=1011$ \\
Portugal & $72 \%$ & $\mathrm{n}=1000$ \\
Switzerland & $62 \%$ & $\mathrm{n}=1011$ \\
Nigeria & $26 \%$ & $\mathrm{n}=1195$ \\
\hline
\end{tabular}

gins and the magnitude of these concerns, nor do the results indicate what these convictions may mean when it comes to possible abatement policies, their social and economic consequences, and the possible associated costs and risks. Thus, prior to any empirical examination of the possibly ambivalent or robust public concern about global warming, one needs to inquire more thoroughly into the basic common sense understanding of the role nature and climate play among individuals in modern societies.

\section{SOCIAL CONDUCT AND TRUST}

One possible point of departure toward such an understanding is the idea that among the significant attributes of the everyday conceptions of nature is a basic sense of trust and sense of good will that is routinely extended to natural processes, for example, toward the sun's radiation as a constant source of warmth or the fundamental temperature balance of the globe. It can be assumed that such trust is neither universal nor independent of societal and cultural conditions but that it emerges in the course of the transformation of societies into entities that are to a growing extent less immediately dependent on environmental constraints (Stehr 1978, p. 1-17). However, there may well be aspects of trust habitually extended toward cli- 
mate that are much more common throughout society and history and therefore also more universal than trust that is imparted to social institutions, for example, religion, science or the state. For Anthony Giddens (1990, p. 92) such a basic trust constitutes an element of the individual 'need' for ontological security. Ontological security has to do phenomenologically speaking with 'being-in-the-world'. Indeed, such a form of trust in the reliability of non human objects' may be 'based upon a more primitive faith in the reliability and nurturance of human individuals' (Giddens 1990, p. 97). Sociologists identified with the so-called functionalist perspective have tended to emphasize the crucial role of trust in social relations in general and social order in particular. Trust serves to maintain social solidarity and reinforces social control. According to this view, trust grounds mutual expectations and assures the predictability and transparence of social situations (Parsons 1954, Luhmann 1973, Barber 1983, Fukayama 1995). The rational choice model, in contrast, stresses the individual's calculated approach to trust in social contexts (e.g. Coleman 1990; for a critique of this approach see Fukayama 1995). But any encounter with climate should have different qualities and features than the confrontation with technology; for example, especially modern, rapidly changing technology that can often be experienced as a source of insecurity and even the destruction of the familiar in everyday life.

Trust indeed is a basic building block of social behavior. It is the glue that holds society together. It signals reliability, security and even predictability. Without reciprocal trust, social conduct would be impossible. It can be safely assumed that the confidence that one is able to carry on extends not merely to social institutions and individuals but to environmental conditions as well, although this does imply that the environment is not from time to time seen to be at risk and hazardous. At the same time, the trust that is extended toward climatic and other environmental processes provides for an important measure of relief from immediate concerns about climate and therefore offers room for action and reflection with respect to other pressing issues in everyday life. The trust extended to nature in modern society is not captured in opinion surveys, however. The degree to which individuals in many cultures and throughout history have imparted a general sense of trust toward particular features of their climate, especially its robustness, consistency and predictability, accounts perhaps for the broad consensus that emerges in surveys when it comes to questions about climate and climate change.

In the past, such confidence was perhaps nurtured more by mythology than by direct experiences with the environment. But as the result of the extensive social transformation of nature into a socially constituted environment in modern society, climate is experienced, with good reason, as extremely dependable and serves as a trustworthy background for much of social conduct. The extent to which weather and climate are directly confronted 'out there' has been reduced to a significant degree. Thus, climate for us-filtered or shielded by the creation of 'total environments', for example, at home, at work, and on the way between the two-becomes a largely taken-for-granted setting.

The trust societies extend to climate and the confidence climate inspires by repeatedly producing the expected effects does not imply that the same weatherrelated phenomena may not be interpreted by different communities in entirely different ways. Mary Douglas ([1970] 1975, p. 234-235), for example, relates observations from her fieldwork in Africa about contradictory interpretations of similar climatic features by neighboring communities. One community perceives the hot dry season as unbearably hot and longs for rain. The adjacent community across the river views the same weather as pleasantly cool and dreads the onset of the rainy season. In both cases, perceptions about the nature of the weather and its effects are sustained by trust in the equilibrating forces of nature.

More generally, what are some of the quintessential relations that best describe our typical encounters with climatic phenomena? The relationship to natural events in which we primarily act as spectators and the experience of nature as an impartial reality seem to stand out in this regard.

If one crudely distinguishes between the options available to us of taking on or being forced to accept the role of an active agent or that of a spectator in a context of social action, then the rather typical role individuals are willing to accept with respect to climate is that of the onlooker. In distinction to other parts and features of the environment that have always been actively managed, climate has not been seen as influenced by human conduct. It has been managed verbally or cognitively, but for centuries the typical human relation to climate has nevertheless been passive. At the same time, many communities throughout history were convinced that they were able to be more than mere spectators when it came to the weather. Techniques of weather control are widespread. However, their success and the belief in their effectiveness depend to a large extent on convictions about the normality of climate patterns; that is, attempts to bring on rain will likely be linked to beliefs and 'objective' signals (increasing cloud cover) indicating the proximity of the rainy season.

One of the significant, perhaps anthropological, constants, of social life is its stratified form. Nonetheless, there are social institutions that at least aspire to be 
and vigorously communicate that they are neutral and impartial in their conduct toward members and clients. However, the physical conditions and context within which social interaction takes place achieves perhaps a degree of impartiality that is unrivaled in social conduct. Both space and climate-as a dual foundation of social organization - are characterized by an unparalleled degree of impartiality and consistency of behavior. As Georg Simmel ([1908] 1992, p. 772) observes in the context of a discussion of the relevance of space for social conduct: 'Space as a basis for social organization has the very attributes of impartiality and evenhandedness of behavior that turn such conduct into a correlate of the way in which the state is acting to toward all its subjects.' If nothing else, the modern state and the judicial system indeed aspire to achieve such impartiality in its dealing with its subjects. But whatever social differentiation and inequality that evolves with reference to space, for example, place of residence, would appear to be more 'rational' than differentiation linked to ascriptive factors such as kinship or unearned income.

Local or regional emancipation from climate, however, does not preserve the essential impartiality about climate. On the contrary, efforts to standardize climate through air conditioning, for instance, imply stratified climate experiences. The effect of climate now depends on the ability of the individual to pay for a partial withdrawal from the natural climate and the creation of an anthropogenic climate. The emancipation from certain features of the climate (temperature and humidity) also has profound demographic, social and economic consequences. Witness for instance the gain in population beginning in the 1970 s and 1980 s in the Southern and Southwestern United States.

\section{EXTREMES AS ACCIDENTS AND TRIGGERING EVENTS}

It is only as the trust we bestow on nature is disappointed-for example, as the result of extreme weather events - that we begin to realize how profound our confidence in the recurrence of natural patterns happens to be. One of the keys to understanding the social construct of climate is not accomplished by examining the semantics of 'normal' climate, but rather by examining how climatic extremes are dealt with and explained by society. An assessment of extremes and an account of their nature can reveal the grounds for what is normal and confidence that this is a correct view.

Climatic extremes are triggering events. Discourse about climatic extremes serves to assure, not unlike punishment of deviant conduct, that extremes are events that digress from more accepted common as well as normal patterns.

The social construct of climate is part of the collective consciousness (or, conscience collective). Following Emilé Durkheim's ([1893] 1964, p. 79) classical definition, the collective or common conscience refers to the 'totality of beliefs and sentiments common to average citizens of the same society' that forms 'a determinate system which has its own life'. The conscience collective is, in other words, independent from the particular conditions in which individuals find themselves, it is more than the sum of its parts and it constrains the individual. The sense in which Emile Durkheim introduced this notion was that any manifest deviation from accepted public, shared normative standards constitutes a kind of offense and is interpreted by society as a moral breach that has to be healed. Durkheim ([1893] 1964, p. 81) refers to the example of crime to make the point that it is not the criminal act that shocks because it is criminal, but rather some action is criminal because it offends the conscience collective: 'We do not reprove it because it is a crime, but it is a crime because we reprove it.' Durkheim also observes that the effect of punishment in terms of deterrence is quite limited. The real function of punishment is to maintain social cohesion.

Not in strict analogy necessarily, but resonating with Durkheim's notions, one is able to make the make the point that climatic extremes affirm the normality of climatic conditions. Extremes are events that trigger and strengthen convictions that climate is constant and that a return to its normal state can be reliably be expected. Normality compensates for extremes, it is a kind of celebration of the common sense consciousness that climate can be trusted to be consistent.

\section{CONCLUSIONS}

How will environmental conceptions formed long ago and sustained during centuries of increasing emancipation from risky climatic conditions respond to an uncertain future in which certainty and trust in normality of climate may not be the norm any longer? We may have 'forgotten' nature but nature may be about to remind us of its existence (Serres [1992] 1995, p. 29). How will we respond? Will it be possible to produce a new social consensus or shared comprehension of climate, let alone policies, under conditions that may have destroyed age-old environmental representations?

The foregoing assessment suggests: (1) modern environmental consciousness is based on trust in the normality of climate and the perception that extremes are therefore fortuitous events as well as an affirmation 
of normality; (2) people experience natural events mainly from a spectator's point of view; and (3) people are convinced that natural events are impartial, while the shape of future society is increasingly decision dependent and intensive (Luhmann 1991, p. 6, Stehr 1994). Climate is perceived by significant segments of the public in modern society as decision-neutral. Thus it may be difficult to formulate and implement appropriate political decisions

One of the most fundamental questions climate research and climate policy may therefore soon face is the possibility that the foundation of trust on which our relationship to nature depends can, in the view of the very serious message of scientists, no longer be assumed. Scientists of course speak with different voices and there are often conflicting points of view. As a result, there is a serious question of credibility. The trust that the public and policy-makers extend to the scientific community itself is undermined. In short, the dual threat to the trust that is vested in nature and the trust in the credibility of science pose particularly difficult problems today.

Acknowledgements. I am grateful to William Catton, Aaron Cicourel, Ralph Matthews and Volker Meja for critical feedback. Research on this paper was supported by a visiting scientist position in the GKSS Research Centre, Geesthacht, Germany.

\section{LITERATURE CITED}

Barber B, (1983) The logic and limits of trust. Rutgers University Press, New Brunswick, NJ

Bergesen HO, Parmann G (1994) Green globe yearbook of international cooperation on environment and development. Oxford University Press, New York

Böhme G (1992) Was ist Natur? Charaktere der Natur aus der Sicht der modernen Naturwissenschaft. In: Böhme G (ed) Natürlich Natur. Über Natur im Zeitalter ihrer technischen Reproduzierbarkeit. Suhrkamp, Frankfurt am Main, p $56-76$

Bourdieu P (1994) Rethinking the state: genesis and structure of the bureaucratic field. Sociological Theory 12 : $1-18$

Brückner E (1890) Klimaschwankungen seit 1700. Nebst Bemerkungen über die Klimaschwankungen der Diluvialzeit. Hölzel, Wien

Cicourel AV (1964) Method and measurement in sociology. The Free Press, New York

Coleman J (1990) Foundations of social theory. Harvard University Press, Cambridge, MIA

Douglas M (1975) Environments at risk. In: Douglas $M$ (ed) Implicit meanings. Essays in anthropology. Routledge and Kegan Paul, London, p 230-248

Dunlap R, Gallup GH Jr, Gallup AM (1994) Of global concern. Results of the health of the planet survey.' Environment (Wash DC) 35:7-15,33-39

Durkheim E (1964) The division of labor in society. The Free Press, New York
Durkheim E (1965) The elementary forms of religious life. Free Press, New York

Elias $N$ (1971) Sociology of knowledge: new perspectives Sociology 5:149-168,335-370

Elias N (1982) The civilizing process, Vol 2: power and civility. Blackwell, Oxiord

Foucault M (1973) The order of things. An archeology of the human sciences. Vintage Books, New York

Fukayama F (1995) Trust: the social virtues and the creation of prosperity. The Free Press, New York

Gamson W, Modigliani A (1989) Media discourse and public opimon on nuclear power. Am J Sociology 95:1-37

Giddens A (1990) The consequences of modernity. Stanford University Press, Stantord

Godelier M (1986) The mental and the material. Thought, economy and society. Verso, London

Greider T, Garkovich L (1994) Landscapes: the social construction of nature and the environment. Rural Sociology 59:1-24

Hannigan JA (1996) Environmental sociology. A social constructionist perspective. Routledge, London

Henderson-Sellers A. (1990) Australian public perception of the greenhouse effect. Clim Change 17:69-96

Lacey C, Longman D (1993) The press and public access to the environment and development debate. Sociological Rev 41:207-243

Lowe P, Morrison D (1984) Bad news or good news: environmental politics and the mass media. Sociological Rev 32 : $75-90$

Luhmann N (1973) Trust and power. Wiley, New York

Luhmann N (1991) Soziologie des Risikos. de Gruyter, Berlin

Marsh GP (1965) Man and nature. Harvard University Press, Cambridge, MA

Mazur A (in press) Global environment in the news: 1987-90 vs 1992-96. Int Sociol

Mazur A, Lee J (1993) Sounding the global alarm: environmental issues in the US national news. Soc Stud Sci 23: $681-720$

Parsons T (1954) Essays in sociological theory. The Free Press, Glencoe, IL

Pierce JC, Lovrich NP, Tsurutani T, Abe T (1987) Environmental belief systems among Japanese and American elites and publics. Polit Behav 9:139-159

Samdahl DM, Robertson R (1989) Social determinants of environmental concern: specification and test of the model. Environ Behav 21:57-81

Semple EC (1931) The geography of the Mediterranean region. Its relation to ancient history. Henry Holt and Company, New York

Serres M (1995) The natural contract. The University of Michigan Press, Ann Arbor

Simmel G (1992) Soziologie. Untersuchungen über die Formen der Vergesellschaftung. Cesamtausgabe: Vol 11 Suhrkamp, Frankfurt am Main

Steger MAE, Pierce JC, Steel BS, Lovrich NP (1989) Political culture, postmaterial values, and the new environmental paradigm: a comparative analysis of Canada and the United States. Polit Behav 3:233-254

Stehr N (1978) Man and the environment: a general perspective. Arch Philos Law Soc Philos 74:1-17

Stehr N (1994) Knowledge societies. Sage, London

Stehr N, von Storch H (1995) The social construct of climate and climate change. Clim Res 5:99-105

Stehr N, von Storch H, Flügel M (1995) The 19th Century discussion of climate variability and climate change: analogies for the present? World Resour Rev 7:589-604

Manuscript received: January 7, 1997

Revised version accepted: August 12, 1997
Editorial responsibility: Chris de Freitas, Auckland, New Zealand 